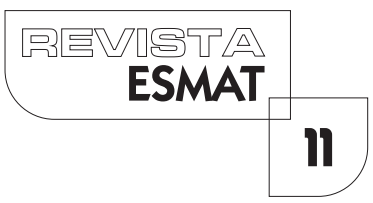

\title{
SUSTENTABILIDADE NA ADMINISTRAÇÃO PÚBLICA
}

SUSTAINABILITY IN PUBLIC ADMINISTRATION

Suyene Monteiro da Rocha

Doutoranda em Biodiversidade e Biotecnologia da Amazônia Legal - Programa BIONORTE. Mestre em Ciência do Meio Ambiente - UFT. Professora Assistente na Universidade Federal do Tocantins. Professora do Programa Mestrado Interdisciplinar Prestação Jurisdicional e Direitos Humanos - UFT. Líder do grupo de pesquisa CNPq: Políticas Públicas Ambientais e Sustentabilidade.

Renata Rodrigues de Castro Rocha

Doutora e Mestre em Ciência Florestal pela Universidade Federal de Viçosa (UFV), Minas Gerais. Professora Ajunta do curso de Direito da Universidade Federal do Tocantins (UFT). Professora do Programa Mestrado Interdisciplinar Prestação Jurisdicional e Direitos Humanos UFT.

Pedro Donizette Biazotto

Advogado, professor de Direito Civil, graduado em Direito e História, pós-graduado em Instituições do Direito Processual Civil. Mestrando do Programa Mestrado Interdisciplinar Prestação Jurisdicional e Direitos Humanos - UFT.

André Henrique Oliveira Leite

Escrivão Judicial no Juizado Especial Cível da Comarca de Gurupi-TO. Professor de Direito Administrativo e Direito Penal pelo Centro Universitário UNIRG, em Gurupi-TO. Graduado em Direito pela Universidade Federal de Goiás. Pós-Graduado em Organização do Poder Judiciário pela FAEL. Mestrando do Programa Mestrado Interdisciplinar Prestação Jurisdicional e Direitos Humanos - UFT

\section{RESUMO}

trabalho aborda a importância do comprometimento da Administração Pública na promoção e compatibilização entre o desenvolvimento, o progresso, o atendimento às necessidades da população e a sustentabilidade na utilização dos recursos naturais. Tendo o Estado, a Administração Pública, papel fundamental na implementação de uma 
economia sustentável, seja pelo fato de ser grande consumidor de produtos e serviços, seja por ser o ator fundante do processo de formação da consciência coletiva, analisou se a política de gestão ambiental desenvolvida pelo Ministério do Meio Ambiente com vistas a sugerir as práticas ao público alvo do minicurso. Verificou se que muitas práticas são passíveis de replicação, sendo o fomento a esta propagação o principal objetivo deste trabalho.

PALAVRAS-CHAVE: Administração pública; Gestão ambiental; Recursos naturais; Desenvolvimento sustentável.

\section{ABSTRACT}

The paper discusses the importance of Public Administration commitment to promote and reconcile development, progress, meeting needs of the population and sustainability in the use of natural resources. Since the State, the Public Administration, plays a fundamental role in the implementation of a sustainable economy, either because it is a major consumer of products and services, or because it is the founding actor of the collective conscience formation process, it analyzed whether the environmental management policy Developed by the Ministry of the Environment with a view to suggesting the practices to the target audience of the mini course. It was verified that many practices are subject to replication, and the promotion of this propagation is the main objective of this work.

KEYWORDS: Public administration; Environmental management; Natural resources; Sustainable development.

\section{A E(IN)VOLUÇÃO DO PROBLEMA AMBIENTAL}

aumento populacional e a práxis capitalista fez com que nos últimos séculos se passasse a visualizar de modo muito evidente os sinais de exaustão da natureza e os efeitos do desequilíbrio ecológico causado pela exploração irracional dos recursos naturais, bem como o agravante do crescente descarte de resíduos do consumo humano.

Em que pese a curva de exploração capitalista ter ampliado a degradação ambiental ainda a partir do século XVIII, notadamente com o advento da Revolução Industrial, pode-se afirmar que apenas após a Segunda Guerra Mundial, notadamente na segunda metade do Século XXé que esse impacto tornou-se efetivamente agravante. 
Fittipaldi (2008) destaca que a humanidade, depois de séculos de danos e exploração, se viu diante de uma nova realidade, passando a se obrigar a usufruir os recursos de forma sustentável, sob pena de, em não o fazendo, colocar em risco a própria existência humana. Isso imporia uma modificação completa no comportamento de exploração da sociedade.

Dias (2006) também assevera que, em que pese ter sido o período de maior evolução, foi o período em que o homem mais gerou meios capazes de levar à própria extinção.

Nosso sistema econômico de desenvolvimento tem a modernização como desculpa para essa sociedade conhecida como desenvolvida. No entendimento de Guimarães (2009), os modelos de sociedades capitalistas modernas se inserem num referencial de hegemonia dos grupos localizados no norte do mundo, notadamente após o fim da bipolarização.

Observa-se ainda que a industrialização, a urbanização, o desenvolvimento científico e tecnológico, o crescimento do sistema de comunicação de massa, o encurtamento das distâncias e a aceleração na velocidade da troca de informações, a evolução dos meios de transporte, o estímulo ao consumo desenfreado, o aumento das disparidades sociais e econômicas locais e globais, o aumento da pressão por recursos naturais e a consequente degradação ambiental são características intrínsecas a esse processo de globalização e modernização.

Tal modelo de desenvolvimento é gerador de desigualdades sociais tanto em termos regionais quanto globais. Portanto, as desigualdades geradas pelo atual modelo de desenvolvimento adotado na maior parte das sociedades trazem à tona uma discussão sobre os valores sociais pelos quais os grupos humanos são regidos. Hoje em dia, parte da sociedade acredita que a qualidade de vida está diretamente atrelada à capacidade de consumo de cada cidadão, fato que gera grandes consequências ambientais ante a incapacidade de se restabelecer a natureza degradada na mesma velocidade em que se degrada.

A degradação que esse modo de produção vem causando não permitiu mais que suas consequências fossem ignoradas. A partir da segunda metade do Século $X X$, diversos e sequenciais tratados e acordos foram discutidos e assinados no sentido de se minimizarem tais impactos. DIAS (2006) lembra que, em 1962, o Livro Primavera Silenciosa de Rachel Carson expôs os perigos do DDT (Dicloro-Difenil-Tricloroetano), primeiro pesticida moderno, fato que causou grande repercussão na opinião pública.

Em 1968, o manifesto do Clube de Roma iniciou o debate contemporâneo ambiental. Posteriormente foi criada, nos Estados Unidos, a National Environmental Policy Act (NEPA), que se tornou a primeira agência nacional de proteção ao meio ambiente. Sequencialmente, em 1971, o Manifesto Menton, que leva o mesmo nome da cidade francesa onde foi assinado, trouxe um documento firmado por 2.200 cientistas de 23 países, alertando os problemas decorrentes do consumo desenfreado. 
Dino (2006) destaca que a declaração de Estocolmo, em 1972, diz que o ser humano tem direito à vida num meio ambiente equilibrado. Antes de 1972, via-se o meio ambiente de forma fragmentada e a visão sistêmica e holística deste somente se fortaleceu depois da conferência de Estocolmo. A declaração é a manifestação de uma expectativa, e não é coercitiva; trata-se de uma carta de boas intenções a inspirar os países a incorporarem os mandamentos jurídicos no âmbito ambiental.

Em 1973, foi proposto por Maurice Strong o conceito de eco desenvolvimento, no qual se considera que a satisfação das necessidades das gerações futuras deve ser garantida, mas que devemos utilizar os recursos naturais com mais sapiência, buscando garantir a qualidade de vida das pessoas de hoje sem sacrificar as gerações futuras.

Posteriormente, no final da década de 1980, o economista Ignacy Sachs desenvolveu a ideia apresentada por Strong e deu origem ao conceito de desenvolvimento sustentável que, também, tem como uma de suas bases o comprometimento de deixar um grande legado natural às gerações futuras, além de assegurar algum tipo de alternativa para o crescimento aos países em desenvolvimento e pobres (BURSZTYN, M. \& BURSZTYN, MA., 20I0).

○ surgimento da expressão "desenvolvimento sustentável" com o Relatório Brundtland, em 1987, é o elo que faltava entre as ciências da economia e da ecologia (BURSZTYN, M. \& BURSZTYN, MA., 20I0). Por um lado, a economia está tentando considerar cada vez mais o custo ecológico; por outro, a ecologia está mostrando que precisamos dos recursos naturais para suprir nossas necessidades, e isso custa caro para o Planeta.

Pode-se dizer que a expressão "desenvolvimento sustentável" passou a permear vários espaços: no governo, nas empresas, na sociedade civil organizada, na mídia e na academia (BURSZTYN, M. \& BURSZTYN, MA., 20 I0). Apesar disso, há controvérsias sobre essa expressão que parece ser formada por duas ideias contraditórias/antagônicas, dependendo de como se entende o conceito de desenvolvimento e o conceito de sustentabilidade.

$\bigcirc$ conceito de sustentabilidade possui diferentes perspectivas. Com o despertar da opinião pública mundial para o problema da degradação ambiental nos anos 60 e com a realização da primeira conferência mundial sobre o meio ambiente em Estocolmo, em 1972, (Conferência das Nações Unidas sobre o Meio Ambiente Humano), o conceito de desenvolvimento sustentável adquiriu um significado distinto daquele que até então Ihe era atribuído.

Na opinião de ROMEIRO (2003), desenvolvimento sustentável se entendia como um processo de crescimento econômico contínuo, autossustentado por um círculo virtuoso provocado pelo aumento da taxa de investimento, que conduz ao crescimento e à diversificação da demanda, o que, fechando o círculo, amplia as oportunidades de investimento. $\bigcirc$ crescimento econômico era visto como condição necessária e suficiente para a prosperidade e elevação do bem-estar das massas. 
Em 1983, a ONU formou a Comissão Mundial sobre o Meio Ambiente e o Desenvolvimento (CMMAD), com o objetivo de examinar as relações entre o Meio Ambiente e o Desenvolvimento, a qual foi presidida pela primeira-ministra da Noruega, Gro Harlem Brundtlsnd (DIAS, 2006). Em 1985, foi realizada a Convenção de Viena e, em 1987, o Protocolo de Montreal, tratado internacional, segundo o qual os países signatários se comprometem a substituir as substâncias que interagem com o ozônio, destruindo-o, na parte superior da estratosfera, conhecida como ozonosfera.

A Conferência do Rio de Janeiro sobre Meio Ambiente e Desenvolvimento, realizada em 1992, resultou em uma pauta de ações denominada Agenda 2 I Global. Entre os trabalhos já realizados em prol do meio ambiente é sem dúvida um dos mais importantes, por ser um documento que contém compromissos no qual cada país participante seria responsável por incorporar às suas políticas públicas princípios com base no desenvolvimento sustentável, com o objetivo de compatibilizar a melhoria da qualidade de vida da população, proporcionando o crescimento econômico em sintonia com o meio ambiente.

Em 1997, foi realizada a terceira Conferência das Partes; nesta, houve entendimento da grande relação entre os temas ambientais e econômicos. Um ponto marcante foi a criação do protocolo de Quioto, que estabeleceu metas a serem cumpridas até 2012, e meios para o seu cumprimento. Nele, os países industrializados deveriam cortar suas emissões e deixar seus níveis abaixo dos de 1990.

Em 2002, aconteceu a Rio + 10, realizada em Johanesburgo na África do Sul, que teve o papel de tratar da implementação das decisões tomadas anteriormente na Conferência do Rio. Em 2004, foi realizada a reunião Ministerial da $10^{a}$ Conferência das Nações Unidas sobre mudanças climáticas (COP I 0) com o objetivo maior de debater a implementação do protocolo de Quioto, que entrou em vigor em 16 de fevereiro de 2005; também foram discutidos os 10 anos da Convenção da ONU sobre mudanças do clima (SOUZA, 2008).

A Conferência das Nações Unidas sobre Desenvolvimento Sustentável, a Rio +20, foi realizada de 13 a 22 de junho de 20 I2, na cidade do Rio de Janeiro. A Rio + 20 foi assim conhecida porque marcou os 20 anos de realização da Conferência das Nações Unidas sobre Meio Ambiente e Desenvolvimento (Rio-92) e contribuiu para definir a agenda do desenvolvimento sustentável para as próximas décadas. $\bigcirc$ objetivo da Conferência foi a renovação do compromisso político com o desenvolvimento sustentável, por meio da avaliação do progresso e das lacunas na implementação das decisões adotadas pelas principais cúpulas sobre o assunto e do tratamento de temas novos e emergentes.

Recentemente, entre os meses de novembro e dezembro de 20 I5, foi realizada, em Paris, a $2 I^{\text {a }}$ Conferência das Partes (COP 2 I), na qual foi adotado um novo acordo global que busca combater os efeitos das mudanças climáticas e reduzir as emissões de gases de efeito estufa. $\bigcirc$ documento, chamado de Acordo de Paris, foi ratificado pelas 
195 partes da Convenção-Quadro das Nações Unidas sobre Mudança do Clima (UNFCCC) e pela União Europeia. Um dos objetivos é manter o aquecimento global "muito abaixo de $2^{\circ} \mathrm{C}$ ", buscando ainda "esforços para limitar o aumento da temperatura a $1,5^{\circ} \mathrm{C}$ acima dos níveis pré-industriais".

\section{SUSTENTABILIDADE - UM CONCEITO BASILAR}

Atualmente fala-se muito em desenvolvimento sustentável, em qualidade e proteção ambiental, em responsabilidade social, em política ambiental, em critérios socioambientais etc. Por isso, muitos têm sido os sentidos conferidos à questão ambiental e, especificamente, à expressão "desenvolvimento sustentável".

Silva, Rosini e Rodrigues (2009) afirmam que o conceito de desenvolvimento sustentável, ligado à preservação ambiental, é uma ideia recente, que somente após se tornarem evidentes os danos provocados ao meio ambiente pelo crescimento econômico e a industrialização, debates, discussões e estudos em busca de alternativas para manter o desenvolvimento sem esgotar os recursos naturais iniciaram-se.

Segundo Freitas (2007), a sustentabilidade tem sido definida como uma fórmula resultante de um tipo de desenvolvimento que é economicamente viável, socialmente responsável e ecologicamente correto. Mas não existe sustentabilidade sem o desenvolvimento de uma mentalidade que respeite a vida em suas multiplicidades. Para ela, a ideia de sustentabilidade "é incompatível com o culto ao efêmero, com o desrespeito ao outro diferente, com a ausência de crítica e transparência e com a impossibilidade de mudança e ruptura" (FREITAS, 2007, p. 77). Nesse sentido, ela define sustentabilidade como "a escolha de um mundo futuro, com o desenvolvimento de um espírito de coletividade, de respeito ao espaço público e de participação democrática". (FREITAS, 2007, p. 79).

Há a necessidade de criar novos paradigmas, pois o atual parece não dar conta de uma perspectiva de futuro. $\bigcirc$ modelo econômico atual tem suas bases fundadas no ganho em curto prazo, na concorrência destruidora e na redução da vida social ao seu aspecto econômico. "O mundo [...] não é simplesmente uma fonte de recursos inesgotáveis, de homens descartáveis, de sociedades reduzidas a números, de trabalhos precários e de empresas predadoras do ambiente e do futuro". (FREITAS, 2007, p. 7879). Exige-se, portanto, um novo paradigma para o desenvolvimento, que compatibilize crescimento econômico, qualidade de vida, respeito à alteridade e aos direitos das gerações futuras. Binswanger (2002, p. 4I), por sua vez, afirma que "desenvolvimento sustentável significa qualificar o crescimento e reconciliar o desenvolvimento econômico com a necessidade de se preservar o meio ambiente".

É preciso esclarecer, como bem salientou Proops et al (2002, p. I06), que sustentabilidade é um processo contínuo, e não uma meta a ser atingida. Exige que se projete um cenário futuro, "uma visão do estado do mundo em direção ao que desejamos avançar". (PROOPS et al, 2002, p. 106). 
Nesse sentido, Krause, analisando a questão da sustentabilidade, diz que apesar dos mil e um encantos e da miríade de definições, a sustentabilidade vai muito mais longe do que se pretende ao qualificá-la simplesmente como atributo de um tipo de desenvolvimento. É um projeto de sociedade alicerçado na consciência crítica do que existe num propósito estratégico como processo de construção do futuro. Vem daí a natureza revolucionária da sustentabilidade. (KRAUSE, 2002, p. 16).

Assim, com o advento do conceito de desenvolvimento sustentável, a variável ambiental passou a integrar, de forma obrigatória, o conceito de gestão e de pensamento estratégico nas organizações (SILVA, 2009, p. 28).

Por isso, segundo Silva (2009), a questão ambiental deixou de ser um assunto de mero modismo ou mesmo uma preocupação passageira, passando a integrar as políticas organizacionais. Isso, graças à introdução dos conceitos de sustentabilidade e desenvolvimento sustentável no rol das discussões empresariais.

○ comportamento atual da sociedade é expressão de uma cultura de consumo e descarte. Só por meio de um processo de reeducação será possível haver mudança cultural. As pessoas precisam conhecer os problemas socioambientais para terem condição de iniciar um novo caminho que garanta a sustentabilidade (PALMISANO; PEREIRA, 2009).

Outra questão relacionada ao consumo e que merece atenção destacada das organizações, principalmente na Administração Pública, é a cultura do desperdício. Tal prática, comum em nossa sociedade, contribui sobremaneira para o aumento do consumo e para o comprometimento da sustentabilidade da sociedade humana e do Planeta.

A economia brasileira caracteriza-se por elevado nível de desperdício de recursos energéticos e naturais. A redução desses constitui verdadeira reserva de desenvolvimento para o Brasil, bem como fonte de bons negócios. [...] Reciclar resíduos, por exemplo, é transformá-los em produtos com valor agregado. "Conservar energia, água e outros recursos naturais é reduzir custos de produção" (MINISTÉRIO DO MEIO AMBIENTE, 20II).

\section{O CONCEITO DE ADMINISTRAÇÃO PÚBLICA E SUA IMPORTÂNCIA NA IDEIA DE SUSTENTABILIDADE}

A proteção ao meio ambiente não era elemento circundante dos debates institucionais até meados do século $X X$. $\bigcirc$ Estado como interventor direto no processo de mitigação das ações geradas no meio ambiente paulatinamente foi tomando corpo.

Amato (1962, p. 84) conceitua administração pública como "parte da ciência de administração que se refere ao governo, e se ocupa por isso, principalmente, do poder executivo onde se faz o trabalho do governo, $[\ldots]$...

Waldo (197I, p. 6) traz duas definições típicas, embora não as considere 
compreensivas e suficientes, para administração pública. A primeira diz que "Administração Pública é a organização e a gerência de homens e materiais para a consecução dos propósitos de um governo". Na segunda definição, a "Administração Pública é a arte e a ciência da gerência aplicada aos negócios do Estado".

Um conceito mais completo e atual seria aquele que afirma que a Administração Pública constitui importante segmento da ciência da Administração. Ela representa o aparelhamento do Estado e funciona como o instrumento do governo para planejar, organizar, dirigir e controlar todas as ações administrativas, no sentido de dar plena e cabal satisfação das necessidades coletivas e básicas. (Chiavenato, 2008, p. 96).

No Brasil, o primeiro modelo estruturado de administração pública foi implantado pelo governo de Getúlio Vargas na primeira metade do século XX. Inspirado no modelo weberiano: o burocrata. Vargas optou por um regime rígido que pudesse "colocar ordem na casa",

Mais tarde - com a expansão do mercado, o desenvolvimento tecnológico, a globalização da economia no mundo - depois de compreender que a burocracia, dada a sua inflexibilidade, era inadequada em cenários dinâmicos, iniciaram-se as ações para desburocratizar a máquina. Várias medidas, como a criação de programas, comitês, secretarias e outros instrumentos, foram implantadas, porém sem sucesso. Assim, somente em 1995, começa no Brasil a implantação, na administração pública, do chamado modelo gerencial, que visa acabar ou pelo menos reduzir o descompasso entre o dinamismo experimentado pela sociedade do final do século $X X$ e a atuação das organizações públicas.

Segundo Chiavenato (2008), a administração pública gerencial representa um avanço, embora não represente um rompimento com a administração burocrática. Ela é mais flexível. Busca resultados. Enquanto na administração burocrática o interesse público se identifica com o interesse e poder do Estado; na administração gerencial,

busca-se a satisfação dos "clientes", ou seja, o atingimento de metas e resultados na satisfação das necessidades dos cidadãos. Essa mudança se deu porque à medida que o Estado assumia a responsabilidade da concretização dos direitos sociais e crescia em dimensão, foi-se percebendo que os custos com o controle seriam demasiados e, ainda, emperrariam sobremaneira a máquina administrativa.

Está-se, pois, diante de um novo paradigma, "o pós-burocrático. Ele se contrapõe à ideologia do formalismo e do rigor técnico. As exigências são outras: formas flexíveis de gestão, horizontalização das estruturas, descentralização de funções, incentivo à criatividade, adoção de valores e comportamentos que promovam qualidade e eficiência dos serviços públicos". (CHIAVENATO, 2008, p. 107).

Para se lograr êxito nessas mudanças, conceituais e estruturais, tem-se exigido das organizações públicas - e de seus administradores - uma guinada em termos de valores, concepções e práticas, ou seja, uma verdadeira mudança na cultura da administração pública brasileira, de forma que the possibilite adaptar-se às mudanças culturais e às exigências da sociedade do século $X X \mid$. 
Diante dessas novas exigências da sociedade atual, necessariamente foi-se ampliando a importância do Estado no contexto de sustentabilidade. A presença do Estado como agente direto da relação de sustentabilidade se alarga no sentido de não ter o único atributo de promover a consciência e participação social, na geração do desenvolvimento sustentável, o ente administrativo é também um ator dessa relação. Assim, o seu modo de consumo, manuseio e descarte dos recursos naturais também passam a ser revistos e reorganizados.

O dever do Estado de promover a defesa e a preservação do meio ambiente para presente e futuras gerações está insculpido na Constituição, de 1988, no artigo 225:

Todos têm direito ao meio ambiente ecologicamente equilibrado, bem de uso comum do povo e essencial à sadia qualidade de vida, impondo-se ao Poder Público e à coletividade o dever de defendê-lo e preservá-lo para as presentes e futuras gerações.

Os novos cenários que se descortinam na administração pública com o fito de proporcionar a otimização do acesso a serviços e bens estão diretamente ligados à determinação constitucional. A Administração Pública deve se imbuir da função de defesa e preservação do meio ambiente para que possa realizar uma gestão articulada e positiva tanto na espera social como ambiental.

Para que se obtenha êxito, a administração deve estabelecer diretrizes e atividades administrativas e operacionais que proporcionem a realização de planejamento, direção, controle, alocação de recursos, com o objetivo de obter efeitos positivos sobre o meio ambiente, quer reduzindo ou eliminando os danos ou problemas causados pelas ações humanas, quer evitando que eles surjam. (BARBIERI, 2007, p. 25).

Dias (2006, p. 28) considera gestão ambiental "conjunto de medidas e procedimentos que permitem identificar problemas ambientais gerados pelas atividades da instituição, como a poluição e o desperdício, e rever critérios de atuação (normas e diretrizes)"; de posse dos resultados, o administrador público tem a possibilidade de alterar suas práticas construindo um cenário de redução ou extinção dos danos ao meio ambiente.

A ideia de consumo está intrinsecamente ligada à noção de sustentabilidade. $\bigcirc$ Estado, a Administração Pública, tem papel fundamental para sustentabilidade, pois, além de seu poder normativo, é o grande consumidor. Barki (20I I , p. 45) defende que "o Estado como consumidor tem o potencial de fomentar o mercado, e como empregador o de imprimir uma cultura administrativa sustentável”. No Brasil, calcula-se que as compras públicas movimentem, nos diversos níveis de governo, cerca de 10\% do PIB. Em 2013, de acordo com dados do Portal da Transparência do Governo Federal, foram gastos, apenas em despesas diretas do governo, $\mathrm{R} \$ 14$ bilhões em três obras; $\mathrm{R} \$ 8$ bilhões em equipamentos e material permanente; e $\mathrm{R} \$$ |6| milhões em material de consumo. Dado o notável volume de recursos envolvidos, o setor público, 
como consumidor de grande porte, encontra-se em posição privilegiada para criar economias de escala que alavancam as margens de lucros dos produtores e reduzem seus riscos.

AAdministração pública tem a responsabilidade de contribuir no enfrentamento das questões ambientais, buscando estratégias inovadoras que repensem os atuais padrões de produção e consumo, os objetivos econômicos, inserindo componentes sociais e ambientais.

Diante dessa necessidade, as instituições públicas têm sido motivadas a implementar iniciativas específicas e desenvolver programas e projetos que promovam a discussão sobre desenvolvimento e a adoção de uma política de Responsabilidade Socioambiental do setor público.

A Administração Pública tem a potencialidade, portanto, de promover a sustentabilidade agindo em duas frentes: uma como prolatora de normas que imponham práticas de uso racional de recursos naturais, reaproveitamento e descarte correto de resíduos, e outra como reguladora fática de mercado, em razão de seu grande poder de consumo.

As instituições públicas ambientais devem estar estruturadas para serem capazes de cumprir com as suas responsabilidades de propor políticas ambientais compatíveis com as necessidades da sociedade. $\bigcirc$ que vale, é claro, para qualquer instituição pública. Portanto, as decisões deverão ser voltadas para garantir a internalização dos aspectos ambientais nas políticas públicas em geral. Os agentes públicos que atuam em órgãos ambientais dos governos devem ser motivados e capacitados adequadamente para estimularem, nos demais segmentos governamentais e na sociedade em geral, uma modalidade nova de pensar o desenvolvimento e o crescimento econômico (SAWYER, 2010).

No Brasil, a grande maioria das políticas ambientais surge no âmbito do Poder Executivo. Isso porque nas instituições de governo é que estão os técnicos e os especialistas que detêm o conhecimento sobre aspectos complexos, e esses estão comprometidos, salvo algumas exceções, com a solução das demandas emanadas pela sociedade. Mas isso não descarta a fundamental importância do diálogo e da parceria com as universidades, organismos não governamentais e com a sociedade civil que, também, devem ter participação bastante ativa na proposição de políticas ambientais.

Portanto, para vencer o desafio ambiental com o qual nos deparamos hoje, será preciso fortalecer as instituições governamentais, prepará-las para cumprir seu papel de modo efetivo. É preciso partir da premissa de que a questão ambiental perpassa as demais áreas de governo e, para que se alcance o nível de sustentabilidade que se deseja, será preciso internalizar as questões ambientais.

Será preciso que todos os agentes do governo repensem como conduzir suas próprias atividades. Uma mudança de paradigma e de comportamento ante as questões ambientais terá êxito desde que haja esforço do Governo em estabelecer políticas de sustentabilidade apropriadas e mais eficazes, e que se empreendam ações de 
mobilização junto com os agentes de governo, capazes de motivá-los e capacitá-los a empreender esforços no sentido de internalizar as questões ambientais em suas atividades diárias e nos processos de tomada de decisão.

\section{AGENDA AMBIENTAL NA ADMINISTRAÇÃO PÚBLICA (A3P): ORIGEM E FUNÇÃO}

Em 1999, foi implantado, na estrutura do Ministério do Meio Ambiente (MMA), o projeto Agenda Ambiental na Administração Pública (A3P), tendo por finalidade "a revisão dos padrões de produção e consumo e a adoção de novos referenciais de sustentabilidade ambiental nas instituições da administração pública" (MINISTÉRIO DO MEIO AMBIENTE, 2010, p. 30).

Dois anos depois, com o objetivo de chamar a atenção dos gestores públicos para a relevância das questões ambientais e para a importância de se tratar o tema dentro da administração pública, e, ao mesmo tempo, estimulá-los a incorporar "princípios e critérios de gestão ambiental" nas atividades do dia a dia da organização, criou-se o Programa Agenda Ambiental na Administração Pública, ou seja, o projeto é ampliado e transformado em um programa (MINISTÉRIO DO MEIO AMBIENTE, 20 I 0, p. 30).

Em virtude da relevância dos seus trabalhos desempenhados nos seus quatro primeiros anos de atividades, a A3P obteve reconhecimento da Organização das Nações Unidas para a Educação, a Ciência e a Cultura (UNESCO) de quem recebeu, em 2002, o prêmio "O melhor dos exemplos" na categoria Meio Ambiente. Em virtude desse reconhecimento, a A3P foi incluída no Plano Plurianual (PPA) de 2004-2007, aparecendo como ação integrante do programa de Educação Ambiental para Sociedades Sustentáveis, o que se repete no PPA 2008-20 I I. Essa medida garantiu ao programa recursos financeiros que permitiram a implantação efetiva da A3P e seu fortalecimento, "tornando-a um referencial de sustentabilidade nas atividades públicas" (MINISTÉRIO DO MEIO AMBIENTE, 2010, p. 30).

A partir de 2007, a A3P passa a integrar o Departamento de Cidadania e Responsabilidade Socioambiental da Secretaria de Articulação Institucional e Cidadania Ambiental (SAIC), em decorrência da reestruturação do Ministério do Meio Ambiente, e assume posição de relevo nas ações governamentais que buscam gerar um novo compromisso da gestão pública com a sustentabilidade.

Após todo esse processo de estruturação, a A3P assumiu o desafio de "promover a Responsabilidade Socioambiental como política governamental”, contribuindo com o crescimento econômico aliado à sustentabilidade, "por meio da inserção de princípios e práticas de sustentabilidade socioambiental no âmbito da administração pública" (MINISTÉRIO DO MEIO AMBIENTE, 20 I0, p. 30).

Para tanto, a A3P apresenta como seu principal objetivo "estimular a reflexão e a mudança de atitude dos servidores para que os mesmos incorporem os critérios de gestão socioambiental em suas atividades rotineiras" (MINISTÉRIO DO MEIO 
AMBIENTE, 2010, p. 30).

Além desse objetivo, o programa busca ainda:

Sensibilizar os gestores públicos para as questões socioambientais;

Promover o uso racional dos recursos naturais e a redução de gastos institucionais;

Contribuir para revisão dos padrões de produção e consumo e para a adoção de novos referenciais de sustentabilidade no âmbito da administração pública e para a melhoria da qualidade de vida;

Reduzir o impacto socioambiental negativo direto e indireto causado pela execução das atividades de caráter administrativo e operacional. (MINISTÉRIO DOMEIO AMBIENTE, 20। 0, p. 35).

Para a consecução desses objetivos, a A3P estruturou-se em cinco eixos temáticos, quais sejam:

I. Sensibilização e capacitação dos servidores: busca criar e consolidar a consciência cidadã da responsabilidade socioambiental nos servidores, contribuindo para o processo de desenvolvimento de competências individuais e institucionais;

2. Gestão adequada dos resíduos gerados: passa pela adoção da política denominada 5Rs: Repensar, Reduzir, Reutilizar, Reciclar e Recusar, que significa, primeiramente, pensar em reduzir o consumo e combater o desperdício para só então destinar o resíduo gerado corretamente;

3. Licitações sustentáveis: significa adquirir produtos e serviços sustentáveis. Tal prática garantirá não só a conservação do meio ambiente, mas também a melhoria da relação custo/benefício a médio ou longo prazo quando comparadas às licitações e compras que utilizam o critério do menor preço;

4. Uso racional dos recursos naturais e bens públicos: significa usar de forma racional água, energia, madeira e consumir, também de forma racional, papel, copos plásticos, dentre outros materiais de expediente;

5. Qualidade de vida no ambiente de trabalho: visa introduzir ações de desenvolvimento pessoal e profissional, como a capacitação e atividades que busquem garantir saúde e bem-estar aos servidores. Dentre as ações, podem-se citar a ginástica laboral, as campanhas contra o fumo e alcoolismo e outros eventos que incentivem a prática de esportes, a boa alimentação, as relações interpessoais etc. (MINISTÉRIO DO MEIO AMBIENTE, 2010, p. 35).

É importante destacar que a A3P afirma ser "uma decisão voluntária em resposta à compreensão de que o Governo Federal possui um papel estratégico na revisão dos padrões de produção e consumo e na adoção de novos referenciais em busca da sustentabilidade socioambiental" (MINISTÉRIO DO MEIO AMBIENTE, 20 I I, p. I). Ademais, é "um convite ao engajamento individual e coletivo para a mudança de hábitos e a difusão da ação". (MINISTÉRIO DO MEIO AMBIENTE, 20 I I , p. I). 
A Agenda encontra-se em harmonia com o princípio da economicidade e ao mesmo tempo atende ao princípio da eficiência, a que os órgãos públicos estão obrigados, previsto na Constituição Federal do Brasil. Ademais, as diretrizes da A3P se fundamentam nas recomendações do Capítulo IV da Agenda 2 I que indica aos países o "estabelecimento de programas voltados ao exame dos padrões insustentáveis de produção e consumo e o desenvolvimento de políticas e estratégias nacionais de estímulo a mudanças nos padrões insustentáveis de consumo"; no Princípio 8 da Declaração do Rio/92 que afirma que "os Estados devem reduzir e eliminar padrões insustentáveis de produção e consumo e promover políticas demográficas adequadas"; e ainda na Declaração de Johannesburgo que institui a "adoção do consumo sustentável como princípio basilar do desenvolvimento sustentável (MINISTÉRIO DO MEIO AMBIENTE, 20I0, p. 3 I).

Suas ações são disciplinadas por Portaria. Em 27 de dezembro de 2002, foi publicada a primeira Portaria, a de no 510 , que instituiu a Comissão Permanente da Agenda Ambiental na Administração Pública. A Portaria continha apenas cinco artigos, formalizando, pela primeira vez, a estrutura da A3P para materializar o Programa, restringindo-se apenas a nomear o comitê gestor, sem definir qualquer diretriz.

Em 13 de setembro de 2004, ela é revogada pela Portaria $n^{\circ} 221$, que reformula o Conselho Gestor e também insere no programa o Conselho Consultivo e as Comissões Setoriais, definindo a composição e a competência de cada um desses órgãos.

Em virtude da evolução do programa, que se ampliou e busca por novos desafios, a inclusão de novas diretrizes se fazia necessária. Assim, em 30 de julho de 2008, publicase uma nova Portaria, a de $n^{\circ} 217$, revogando a anterior. Esta nova Portaria institui o Comitê de Implementação da A3P, que substitui o Conselho Gestor e estabelece sua composição e competências. Além disso, reafirma a autorização para que os gestores criem Comissões Setoriais e/ou internas e define como coordenador dos trabalhos do Comitê o Departamento de Cidadania e Responsabilidade Socioambiental da Secretaria de Articulação Institucional e Cidadania Ambiental do Ministério do Meio Ambiente.

Em 2009, o Ministério do Meio Ambiente realizou, por intermédio do Departamento de Cidadania e Responsabilidade Socioambiental da Secretaria de Articulação Institucional e Cidadania Ambiental (DCRS/SAIC), o $1^{\circ}$ Prêmio em Melhores Práticas da A3P. A realização do Prêmio buscou dar visibilidade às práticas bem-sucedidas na área socioambiental, além de reconhecer o mérito das iniciativas dos órgãos e instituições do setor público na promoção da Agenda Ambiental na Administração Pública (A3P). Tal prêmio vem sendo reeditado, de tal sorte que hoje está em sua 6a Edição, denominado "Melhores Práticas de Sustentabilidade".

Atualmente, conforme dados constantes do sítio eletrônico do Ministério do Meio Ambiente, cuja atualização data de junho de 2015, o Programa A3P conta com a participação de 165 instituições públicas das três esferas de governo e no âmbito dos 
três poderes, com termo de adesão assinado. E mais, são 545 órgãos cadastrados na chamada Rede A3P, criada com o objetivo de viabilizar a participação, de maneira mais informal, de outras entidades, até mesmo da iniciativa privada.

Essa necessidade de transformações amplas e duradouras impõe ao poder público um papel estratégico nas ações necessárias à consolidação do desenvolvimento sustentável. Pois, além de possuir considerável movimentação de recursos econômicos, tem capacidade empreendedora, responsabilidade legal e social e detém o poder de regular as relações e a vida da sociedade em geral.

Os governos são chamados a serem parceiros e exercerem um papel estratégico no estabelecimento de novos referenciais. Cabe a eles fazer as leis, normas e estabelecer padrões adequados de produção e consumo, normatizando e estimulando inovações nas áreas tecnológicas e sociais (MACHADO, 2002). Além disso, enquanto consumidora e gestora, a Administração Pública tem a responsabilidade de aplicação dos recursos públicos de forma responsável, incluindo-se, nessa responsabilidade, padrões sustentáveis e práticas ambientalmente corretas.

Nesse sentido, Cavalcanti (2002, p. 3 I) adverte que um aspecto das políticas de governo voltadas para objetivos de sustentabilidade que merece atenção especial é o tratamento a ser dado a atos de consumo e estilos de vida. De um lado, níveis excessivos de consumo de bens e serviços devem ser contidos. De outro, a persuasão para que se consuma mais e mais de cada coisa, nutrida pelos meios de comunicação (a televisão, sobretudo), deve ser revista e posta dentro dos parâmetros de prudência ecológica indispensáveis para a sustentabilidade.

\section{CONCLUSÃO}

É certo que a humanidade não pode parar de consumir, mas é preciso que o consumo não acarrete a inviabilidade da vida humana na Terra. Diante disso, é necessário que o Estado, como órgão máximo de poder das sociedades, promova ações de sustentabilidade, entre as quais as de suscitar em suas próprias atividades o uso racional de recursos naturais, reaproveitamento de materiais e o descarte e tratamento adequado de resíduos.

É necessário um intenso trabalho de conscientização para que a sociedade e as instituições públicas e privadas encampem as ações de sustentabilidade. A Administração Pública, dado o seu poder normativo e seu poder de influenciar o mercado, dada sua condição de grande consumidor, deve portar-se como a principal indutora da mudança de mentalidade e de comportamento, a fim de tornar realidade a compatibilização do progresso e do desenvolvimento com o equilíbrio ambiental, como pressuposto inafastável da sobrevivência da humanidade e de inúmeras formas de vida do Planeta.

A criação do Programa A3P representou grande passo dado pela Administração Pública para a implementação de políticas e ações de sustentabilidade. Urge agora uma 
intensa divulgação do Programa A3P e ações punitivas e principalmente retributivas positivas para que as mais diversas esferas da Administração Pública façam adesão ao Programa, o que induzirá inevitavelmente a uma mudança nas posturas do mercado e nas condutas das pessoas e instituições privadas.

\section{REFERÊNCIAS}

BARBIERI, José Carlos, Gestão Ambiental Empresarial - conceitos, modelos e instrumentos. São Paulo: Saraiva, 2004.

BARKI, Teresa Villac Pinheiro. Direito internacional ambiental como fundamento jurídico para as licitações sustentáveis no Brasil. In: SANTOS, Murillo Giordan; BARKI, Teresa Villac Pinheiro (Coord.). Licitações e contratações públicas sustentáveis. Belo Horizonte: Fórum, 201 I , p. 3.965.

BINSWANGER, Hans Christoph. Fazendo a sustentabilidade funcionar. In: CAVALCANTI, Clóvis (Org.). Meio ambiente, desenvolvimento sustentável e políticas públicas. $4^{a}$ ed. São Paulo: Cortez; Recife: Fundação Joaquim Nabuco, 2002.

BRASIL. Constituição da República Federativa do Brasil : Promulgada em 05 de outubro de 1988. Casa Civil. Subchefia para Assuntos Jurídicos. Diário Oficial da República Federativa do Brasil, Brasília, DF. Disponível em: <http://www.planalto.gov.br/ccivil_03/constituicao/constituicao.htm > . Acesso em 2 fev. 2016.

- MINISTÉRIO DO MEIO AMBIENTE. Adesos a A3P. Disponível em:<http://www.mma.gov.br/responsabilidadesocioambiental/a3p/parceiros/item/94 $17>$. Acesso em 4 fev. 2016

Manual da Agenda Ambiental na Administração Pública - A3P.

Brasília. $4^{\mathrm{a}}$ ed. 2007. Disponível em: www.gespublica.gov.br. Acesso em I ºfev. 2016.

Agenda Ambiental da administração pública . Disponível em: <http://www.mma.gov.br/responsabilidadesocioambiental/a3p > Acesso em 4 fev. 2016

CHIAVENATO, Idalberto. Administração Geral e Pública. $2^{a}$ ed. Rio de Janeiro: Elsevier, 2008.

Administração nos novos tempos. $2^{\mathrm{a}}$ ed. - Rio de Janeiro: Elsevier, 2010. 
DIAS, Genebaldo Freire. Educação e gestão ambiental . São Paulo: Gaia, 2006.

DOWBOR, Ladislau. Posfácio a gestão pública e sustentabilidade, ago. 20 | I D i s p o níve I e $m$ : $<$ https://www.google.com.br/url?sa $=$ t\&rct $=j \& q=\& e s r c=s \&$ source $=$ web\&cd $=1 \& s$ $\mathrm{q} i=2 \& \mathrm{ved}=0 \mathrm{CDkQFjAA \& url}=\mathrm{http} \% 3 \mathrm{~A} \% 2 \mathrm{~F} \% 2 \mathrm{Fdowbor}$.org\%2Fblog\%2Fwpconte nt\%2Fuploads\%2F20 I 3\%2F0 I \%2F I I Posf\%25C3\%25A I cioSampaioaGest\%25C3 \%25A3oP\%25C3\%25BAblicaeSustentabilidade.doc\&ei=Ne5bUt_8J9ShqwGe5IC4 Bw\&usg=AFQjCNHJVFuukDhR22ObFyM8I2gIIPDWg\&bvm =bv.53899372,d.eW0 $>$. Acesso em 4 nov. 2015.

FITTIPALDI, J. N. M. Diretrizes para Implantação de um Sistema de Gestão Ambiental na Universidade Federal Rural de Pernambuco com base na ISO I4.00 I. Monografia. UFRPE, Recife-PE. 2008.

GIANSANTI, Roberto. O desafio do desenvolvimento sustentável. São Paulo: Atual, 1998.

KRAUSE, Gustavo. Prefácio. In: CAVALCANTI, Clóvis (Org.). Meio ambiente, desenvolvimento sustentável e políticas públicas. $4^{\mathrm{a}}$ ed. São Paulo: Cortez; Recife: Fundação Joaquim Nabuco, 2002.

LAYRARGUES, Philippe Pomier. $O$ cinismo da reciclagem: o significado ideológico da reciclagem da lata de alumínio e suas implicações para educação ambiental. In: CASTRO. R.S (org); LAYRARGUES. P. (org); LOUREIRO. C. F. B. (org). MEDEIROS, M; NASCIMENTO, E.P; SAWYER, D. Gestão Pública. Texto elaborado para o curso de especialização em Gestão Pública Ambiental/CDS-UNB. Brasília, 2010.

MOURA, L. A. A. Qualidade e Gestão Ambiental, $3^{\text {a }}$ ed. São Paulo. Ed. Juarez de Oliveira, 2002.

SACHS. Ignacy. Estratégias de transição para o século $X X I$ : desenvolvimento e meio ambiente. São Paulo: Nobel, 1993.

Recebido em: I I/05/2016

Aprovado em: 25/09/2016 